\title{
Higher Prevalence Rates of Smoking in Rural than Urban Areas among School-Going Adolescents in the Lusaka Province, Zambia
}

\author{
Seter Siziya \\ Department of Community Medicine, School of Medicine, University of Zambia, Lusaka, Zambia \\ Email address: Ssiziya@yahoo.com
}

\begin{abstract}
Objectives: The objective of the study was to compare prevalence rates of smoking in schoolgoing adolescents among urban, peri-urban, and rural districts.
\end{abstract}

Design: Secondary analysis of the Zambia Global Youth Tobacco Survey (GTYS) data of 2007.

Main outcome measure: Tobacco smoking status.

Results: Totals of 2378 adolescents in Lusaka urban, 1756 in Kafue per-urban, and 1386 in Chongwe/Luangwa rural districts were enrolled into the study. Smoking rates were $10.5 \%$ in urban, $11.1 \%$ in peri-urban, and $13.5 \%$ in rural districts. After adjusting for age, sex, grade, parental and best friend smoking status, and knowing that smoking is harmful to health, compared to adolescents in Lusaka urban district, adolescents in Chongwe/Luangwa rural districts were $17 \%$ $(\mathrm{AOR}=1.17,95 \% \mathrm{CI}[1.10,1.23])$ more likely to smoke cigarettes. No significant difference in smoking rates was observed between adolescents in urban and peri-urban districts.

Conclusions: The prevalence rate of smoking among adolescents was higher in rural than urban district. Antismoking interventions should be more targeted to adolescents in rural than urban areas.

\section{INTRODUCTION}

Tobacco smoking is increasing in developing countries, and is linked to an increase in socioeconomic status despite the fact that it causes cancer and other diseases.' However, the results on the association between smoking and urbanization have not been consistent. While there was no significant difference in tobacco use between urban and rural children in Cameroon, ${ }^{2}$ Steyn et al ${ }^{3}$ found that smoking patterns were influenced by the degree of urbanization in women of the Cape Peninsula, South Africa. Further, a significantly higher total tobacco consumption in the urban than rural Tongans population was reported by Finau et al. ${ }^{*}$

With limited resources available for tobacco control, it is important that targeted interventions are conducted in areas with higher prevalence of tobacco smoking. And only in such areas would the impact of the intervention be easily evaluated. A pilot tobacco intervention is underway in Lusaka urban district, and a roll-out of the intervention should be in areas with high prevalence of smoking. The current study was conducted to compare smoking prevalence rates among urban, peri-urban and rural districts in the Lusaka province.

\section{METHODS}

\section{Study design and sampling}

Data from the Lusaka-Zambia GYTS conducted in 2007 was used in the current study. A two stage cluster sampling design was used. A total of 25 schools were selected first with probability proportional to their student enrolment size, and 24 $(96.0 \%)$ participated. In the second stage of sampling, classes were randomly selected and 2678 students were sampled, out of whom 2378 (88.8\%) eventually participated in the survey. 


\section{Questionnaire}

A standard GYTS questionnaire with a few countryspecific data was administered to students in their classrooms during one class period. A comprehensive description of the GYTS methodology has been reported elsewhere. . $^{5,6}$
Students were asked the following question, among others: During the past 30 days (1 month), on how many days did you smoke cigarettes? Do your parents smoke? And do any of your friends smoke cigarettes?

\section{Ethical considerations}

The project coordinator for the Zambia 2007 GTYS provided the data for analysis.

\section{Data Analysis}

The GYTS data were analyzed in SPSS 11.5 (Chicago, IL, United States of America). As is the convention in the Global Tobacco Surveillance System (GTSS), current cigarette smoking was defined as having smoked a cigarette, even a single puff, within the last 30 days prior to the survey. ${ }^{5-7}$ A weighted analysis was conducted to obtain the prevalence of current cigarette smoking, as well as other relevant characteristics.

We report results of bivariate logistic regression analysis as unadjusted odds ratios (ORs), while the results from multivariate analysis are reported as adjusted odds ratios (AORs).

\section{RESULTS}

\section{Prevalence of tobacco smoking}

Totals of 2378 students in Lusaka urban, 1756 in Kafue peri-urban, and 1386 in Chongwe/Luangwa rural districts participated in the survey. The prevalence rates for tobacco smoking were $10.5 \%$, $11.1 \%$ and $13.5 \%$ in urban, peri-urban and rural districts, respectively.

\section{Identification of confounding factors}

Table 1 shows that all the factors considered in the analysis were confounding the relationship between district (urban, peri-urban, and rural) and tobacco smoking.

Table 1: Identification of confounding factors

\begin{tabular}{|c|c|c|c|c|}
\hline \multirow[b]{3}{*}{ Factor } & \multicolumn{3}{|c|}{ Exposure (District) } & \multirow[b]{2}{*}{ Outcome (Smoking) } \\
\hline & Urban & Per-urban & Rural & \\
\hline & $\mathrm{N}(\%)$ & $\mathrm{N}(\%)$ & $\mathrm{N}(\%)$ & OR $(95 \%$ ci) \\
\hline Age (years) & \multicolumn{3}{|l|}{$P<0.001$} & $\mathrm{P}<0.001$ \\
\hline$\leq 11$ & $151(6.1)$ & $125(7.0)$ & $86(6.4)$ & 1 \\
\hline$\overline{12}$ & $256(10.6)$ & $148(7.8)$ & $114(6.9)$ & $1.00(0.93,1.09)$ \\
\hline 13 & $404(16.7)$ & $249(12.6)$ & $167(11.0)$ & $0.49(0.45,0.53)$ \\
\hline 14 & $517(22.3)$ & $364(19.7)$ & $260(17.1)$ & $0.61(0.57,0.65)$ \\
\hline 15 & $441(19.1)$ & $333(19.9)$ & $271(21.3)$ & $0.85(0.80,0.90)$ \\
\hline 16 & $343(15.1)$ & $283(17.8)$ & $251(20.3)$ & $1.03(0.97,1.09)$ \\
\hline $17+$ & $250(10.0)$ & $236(15.2)$ & $217(16.9)$ & $2.03(1.92,2.15)$ \\
\hline Sex & \multicolumn{3}{|l|}{$\mathrm{P}<0.001$} & $\mathrm{P}<0.001$ \\
\hline Male & $1281(43.2)$ & $818(45.8)$ & $661(45.3)$ & 1 \\
\hline Female & $1093(56.8)$ & $936(54.2)$ & $714(54.7)$ & $0.85(0.83,0.87)$ \\
\hline Grade & \multicolumn{3}{|l|}{$\mathrm{P}<0.001$} & $P<0.001$ \\
\hline 7 & $1030(44.1)$ & $696(34.6)$ & $576(36.0)$ & 1 \\
\hline 8 & $686(22.5)$ & $475(24.1)$ & $557(26.5)$ & $0.81(0.77,0.86)$ \\
\hline 9 & $660(33.4)$ & $1756(41.3)$ & $244(37.6)$ & $0.90(0.86,0.93)$ \\
\hline Parental smoking status & \multicolumn{3}{|l|}{$\mathrm{P}<0.001$} & $\mathrm{P}<0.001$ \\
\hline None & $1591(77.2)$ & $1060(72.3)$ & $846(71.3)$ & 1 \\
\hline Both & $74(3.4)$ & $83(5.6)$ & $69(5.0)$ & $1.74(1.59,1.92)$ \\
\hline Father only & $354(17.3)$ & $286(19.6)$ & $286(22.1)$ & $0.89(0.83,0.95)$ \\
\hline Mother only & $41(2.0)$ & $40(2.5)$ & $25(1.6)$ & $2.32(2.04,2.63)$ \\
\hline $\begin{array}{l}\text { Best friends' smoking } \\
\text { status }\end{array}$ & \multicolumn{3}{|l|}{$P<0.001$} & $\mathrm{P}<0.001$ \\
\hline None & $1613(69.4)$ & $1054(60.6)$ & $921(69.8)$ & 1 \\
\hline Some & $533(22.0)$ & $487(28.3)$ & $319(21.8)$ & $0.85(0.81,0.89)$ \\
\hline Most & $120(4.7)$ & $126(7.0)$ & $88(5.7)$ & $1.67(1.55,1.79)$ \\
\hline All & $90(3.9)$ & $76(4.2)$ & $48(2.8)$ & $3.89(3.59,4.22)$ \\
\hline $\begin{array}{l}\text { Smoking is harmful to } \\
\text { health }\end{array}$ & \multicolumn{3}{|l|}{$\mathrm{P}<0.001$} & $\mathrm{P}<0.001$ \\
\hline Definitely not & $786(33.8)$ & $628(36.8)$ & $459(31.4)$ & 1 \\
\hline Probably not & $245(10.0)$ & $226(12.5)$ & $147(10.2)$ & $1.38(1.31,1.47)$ \\
\hline Probably yes & $194(7.9)$ & $162(9.1)$ & $138(10.5)$ & $1.48(1.39,1.51)$ \\
\hline Definitely yes & $1141(48.3)$ & $719(41.6)$ & 635 (47.9) & $0.66(0.63,0.69)$ \\
\hline
\end{tabular}

\section{Relationship between District and Smoking}

In bivariate analysis (Table 1), while respondents in a peri-urban district were less likely to smoke compared to respondents in an urban district, respondents in a rural district were more likely to smoke.

After adjusting for age, sex, grade, smoking status for parents and best friends, and knowing that smoking is harmful to health, the results did not significantly change. Compared to respondents in an urban district, respondents in a peri-urban district were $13 \%$ less likely to smoke; and respondents in a rural district were $20 \%$ more likely to smoke (Table 2). 
Table 2: Relationship between district (urban, peri-urban, and rural) and smoking status.

\begin{tabular}{|c|c|c|c|c|}
\hline District & Total & Smoker (\%) & OR $(95 \% \mathrm{Cl})$ & $\mathrm{AOR}^{*}(95 \% \mathrm{Cl})$ \\
\hline Urban & 2378 & 10.5 & 1 & 1 \\
\hline Per-urban & 1756 & 11.1 & $0.95(0.91,1.00)$ & $0.87(0.83,0.92)$ \\
\hline Rural & 1386 & 13.5 & $1.19(1.13,1.24)$ & $1.20(1.14,1.26)$ \\
\hline
\end{tabular}

\section{DISCUSSIONS}

We found a significant relationship between district (urban, peri-urban, and rural) and smoking status. Respondents in a rural district were more likely to smoke cigarettes. This finding contradicts the results of Walker ${ }^{1}$ who reported that the prevalence of smoking was linked to an increase in socioeconomic status; and of Finau et $\mathrm{al}^{4}$ who found significantly higher total tobacco consumption in the urban than rural Tongans population. It further contradicts the findings by Proctor et al, who found no significant difference in tobacco use between urban and rural children in Cameroon.

While it has been generally reported that the prevalence of smoking is higher in developed countries than in developing countries, our finding suggests that this observation may not hold in other populations. Differences in smoking rates may be related to local cultural and social determinants, and not only to economic development. It is important to determine local smoking prevalence rates so that informed interventions may be instituted in areas of high prevalence rates. Factors driving the smoking epidemic should be considered in designing interventions for a targeted population.

There are limitations for the current study. For example, as in any cross sectional study, we cannot ascribe causation to the relationship between district and smoking. Further, the factors were self reported, and bias may have been introduced in our finding to the extent that the mis-reporting by the respondents differed among districts. There is no reason why the rate of mis-reporting should be different among districts. Although it is not possible to determine the magnitude and direction of the bias, it is believed that the effect of bias on the study finding may have been non-significant.
In conclusion, the finding that the prevalence rate of smoking was higher in rural than urban districts suggests that most antismoking interventions should be targeted to rural populations in the Lusaka province.

\section{ACKNOWLEDGMENTS}

The efforts by the research team and the students are gratefully acknowledged for making the survey a success.

\section{REFERENCES}

1. Walker, A.R. Urbanisation of developing populations: what are the health / ill health prospects regarding diseases of prosperity? Urban Health Newsl. 1996;30:20-28.

2. Proctor, M.H., Moore, L.L., Singer, M.R., Hood, M.Y., Nguyen, U.S. and Ellison, R.C. Risk profiles for non-communicable diseases in rural and urban schoolchildren in the Republic of Cameroon. Ethn Dis. 1996;6:235-243.

3. Steyn, K., Kazenellenbogen, J.M., Lombard, C.J. and Bourne, L,T. Urbanization and the risk for chronic diseases of lifestyle in the black population of the Cape Peninsula, South Africa. J Cardiovasc Risk. 1997;4:135-142.

4. Finau, S.A., Stanhope, J.M. and Prior, I.A. Kava, alcohol and tobacco consumption among Tongans with urbanization. Soc Sci Med. 1982;16:35-41.

5. The GTSS Collaborative Group. The global tobacco surveillance system. Tob Control 2006;15:ii1-3

6. Global Tobacco Surveillance System Collaborating Group. Global Tobacco Surveillance System (GTSS): Purpose, production, and potential. $J$ Sch Health 2005;75:15-24.

7. Yang, T., Wu, Y., Abdullah, A.S., et al. Attitudes and behavioral response toward key tobacco control measures from the FCTC among Chinese urban residents. BMC Public Health 2007; 7:248. 